\title{
O PROCESSO DE AFIRMAÇÃO DA ORIENTAÇÃO SEXUAL E SUAS IMPLICAÇÕES NA VIDA FAMILIAR
}

\section{THE PROCESS FOR EXPRESSION OF SEXUAL ORIENTATION AND ITS IMPLICATIONS IN FAMILY LIFE}

\author{
Keith Diego Kurashige(G-UFMS) \\ Aparecido Francisco dos Reis(UFMS/CNPQ)
}

\begin{abstract}
Resumo: Existem muitas implicaçoes sociais em assumir-se homossexual, principalmente na família. Na realidade pós-moderna a tradicional família nuclear modificou-se e nos deparamos diante vários arranjos familiares o que implica dizer que os significados atribuídos por pais e mães heterossexuais à cerca da homossexualidade dos filhos também podem vir a ser diferentes diante às instabilidades dos estamentos tradicionais na contemporaneidade. Porém é inegável o papel da família seja ela como for, no processo de instaurar, refutar, construir ou reafirmar valores, conceitos e preconceitos. Na contemporaneidade as categorias rígidas de fronteiras sociais como a de hierarquia paterfamiliar vem sendo quebrada como também do corpo ideológico onde abre ala para a construção da identidade pessoal dos indivíduos. Nem sempre esse espaço é aberto a diálogos na família, tornando sucetíveis à repressão sexual, estimulando, assim, estigmas por estarem fora da boa conduta tradicional. Este artigo fará uma revisao bibliográfica recente acerca do tema família, orientaçao sexual e sexualidade.
\end{abstract}

Palavras-chave: Família. Pós-modernidade. Homossexualidade.

Abstract: There are many social implications assumed homosexual, especially in the family. In fact post-modern to traditional nuclear family has changed and we face on several living arrangements which imply that the meanings attributed by heterosexual parents to their children about homosexuality may also turn out to be different on the instability of traditional estates nowadays. But it is undeniable is the role of family as she is in the process of establishing, refute, build or reaffirm values, concepts and prejudices. In contemporary categories of rigid social boundaries as the hierarchy has been broken family parents as well as the body opens where ideological wing for the construction of personal identity of individuals. This space is not always open to dialogue in the family, where it becomes susceptible installation of sexual repression thus encouraging stigma for being out of the traditional good conduct. This article will review the recent literature on the topic of family, sexual orientation and sexuality.

Key words: Family. Postmodernity. Homosexuality.

\section{Introdução}

Este trabalho tem por objetivo fazer reflexão acerca do processo e implicações de se

\begin{tabular}{|l|l|l|l|l|l|}
\hline Interfaces da Educ. & Paranaíba & v. 1 & n. 3 & p.93-102 & 2010 \\
\hline
\end{tabular}


assumir como homossexual, transexual ou travesti no contexto familiar, tomando como ponto de partida uma análise da situação familiar na atualidade e como vêm sendo esse processo de aceitação da orientação sexual dos jovens pelos seus familiares. É necessário, no entanto, analisarmos a situação familiar que vem se modificando ao longo da história, pois é nesse campo que se faz a reflexão desse estudo.

A família vem se modificando em suas estruturas no qual a família nuclear tradicional foi e continua sendo em sua grande parte de modo patriarcal, mas vem sofrendo mudanças conforme modificações sociais no aspecto mais amplo. É um processo muito difícil se assumir homossexual, pois além das barreiras enfrentadas na sociedade, existem implicações. São estereótipos preconceituosos sustentados por discursos que promovem a não-aceitação dentro da sociedade e também, mais especificamente, dentro da família. Mais do que incidência de preconceitos contra os homossexuais, a própria sexualidade é velada, tornando-se também uma barreira no processo de se assumir.

O primeiro contato que se faz no que diz respeito ao se assumir como homossexual dentro do contexto familiar, é necessário definir do que se trata a família, no qual abordagens feitas pelas teses de doutorado Família e Homossexualidade, velhas questões e novos problemas, de Ana Paula Uziel (2002) e Pais e mães heterossexuais: Relatos acerca da homossexualidade de filhos e filhas de Roberta da Costa Borges (2009). Tais autores serão mais adiante abordados em alguns temas. Será também essencial autores como Gayle Rubin (2003), Michel Foucault (1989), Adriana Nunan (2003) e entre outros autores que contribuem para a noção acerca da sexualidade. Será explorado esse ponto mais adiante neste trabalho. $\mathrm{O}$ processo de se assumir carece de interpretações por sua complexidade e implicações.

\section{A Família num contexto de mudanças sociais}

Atualmente observamos grandes modificações em que a sociedade passa em todos os campos na transformação cultural, econômico, político, social e tecnológico. Tecendo, desse modo, diferentes relações interpessoais, sexualidade humana e constituição familiar.

Esse período é chamado para uns de pós-modernidade, e para outros de contemporaneidade, modernidade reflexiva ou tardia. Tudo que era sólido na configuração da modernidade como as classes, indústria, cidade, coletividade e demais configurações institucionais são desmanchadas dando lugar à diversidade de comportamentos e opiniões, modo de vida, dentre outros. As tradições ou os valores que foram ou são inculcados pela modernidade, mostram-nos uma sociedade que em grande parte das vezes são intolerantes, diluindo aos novos moldes pós-moderno existentes. Os que eram hierarquizados com pensamentos dicotômicos começam lentamente a serem neutralizadas e passando a ser prelúdio de um igualitarismo.

O pós-moderno não age como na razão objetiva, mas pela subjetividade que acentua a individualidade, tornando, consequentemente, a sociedade mais fluida nos quais, falar de coletividade soa ultrapassado. Desse modo, Santos (2004, p.32) conclui:

Dessa perspectiva podemos dizer que a pós-modernidade no que se refere aos comportamentos humanos abarca e enfatiza a performance, o desempenho, a

\begin{tabular}{|l|l|l|l|l|l|}
\hline Interfaces da Educ. & Paranaíba & v. 1 & n. 3 & p.93-102 & 2010 \\
\hline
\end{tabular}


individualidade e se caracteriza pela efemeridade, rapidez, complexidade, contradição, ambigüidade, tensão, cultura do ter em detrimento do ser, o que provoca um enfraquecimento e distanciamento das relações interpessoais.

A contemporaneidade traz consigo junto às mudanças nas estruturas sociais uma reconfiguração dos modelos familiares em que antes eram delimitadas numa estrutura patriarcal e nuclear e hoje abertas a inúmeras outras possibilidades. Vamos, no entanto, nos delimitar neste artigo nas mudanças ocorridas na família.

O conceito de família tem diversos significados diante várias áreas do conhecimento, porém pode-se ter uma grande convicção de que a família está presente em praticamente todas as sociedades mesmo tendo costumes sexuais e de educação diferentes uma das outras. Estão presentes em toda a história da humanidade e vem sofrendo modificações.

\begin{abstract}
Do ponto de vista antropológico, portanto, o conceito de família tem sido utilizado para se referir à unidade de reprodução biológica e social, criada por laços de aliança, instituídos pelo casamento, bem como por uniões consensuais, por vínculos de descendência, biológicos ou não, entre pais e filhos e, ainda por vínculos de consangüinidade entre irmãos. (DURHAM, 1983 apud BORGES, 2009, p.16).
\end{abstract}

Também podemos definir a família como um conjunto invisível de exigências funcionais que organizam as interações de seus membros, considerando assim como um sistema. Desse modo, para Borges,

[...] no interior da família, os indivíduos podem constituir subsistemas, que podem ser formados pela geração, sexo, interesse e ou função havendo diferentes níveis de poder e nos quais os comportamentos de um membro afetam e influenciam os outros membros. A família, como unidade social enfrenta uma série de tarefas de desenvolvimento, diferindo quanto aos parâmetros culturais, mas possuindo as mesmas raízes universais. (BORGES, 2009, p.16).

As realidades sociais são ficções sociais reconhecidas coletivamente (UZIEL, 2002). Ou seja, o que denominamos família é uma família real e esta é um princípio de construção da realidade social. Este princípio é socialmente construído é inculcado através da socialização que é organizada através da divisão em famílias. Esse princípio é construtivo do habitus, uma estrutura mental individual e coletiva, incorporada com a socialização, lei que orienta a percepção e a prática que fornecem o consenso sobre o sentido do mundo social. (UZIEL, 2002).

O modelo inspirado da sociedade ocidental, a família nuclear, é cada vez mais uma experiência minoritária. A família aparece como uma categoria social mais natural que existe, é porque ela funciona como esquema classificatório e princípio de construção do mundo social. Indiferente às flutuações dos sentimentos, a família se mantém de modo que esteja constituída como entidade unida, unitária, estável e constante.

Há um trabalho simbólico capaz de transformar o que poderia ser obrigação de amar em disposição para tal, dotando cada membro do grupo de generosidade, solidariedade, capacidade de doação, de ajuda. Deste modo, Uziel (2002) argumenta que o sentimento

\begin{tabular}{|l|l|l|l|l|l|}
\hline Interfaces da Educ. & Paranaíba & v. 1 & n. 3 & p.93-102 & 2010 \\
\hline
\end{tabular}


familiar precisa ser constantemente re-investido para que esta ficção possa se perpetuar, é necessário uma adesão à existência desse grupo.

Sendo a família uma unidade de reprodução social, as formas de sociabilidade e as expressões de afeto são orientadas por padrões culturais guiados pela sociedade. Assim, diante da agressão externa de uma sociedade individualista, a família constitui-se como um refúgio.

Desse modo, configura-se a família de forma que,

[...] agora existe uma maior mobilidade para constituição e dissolução dos vínculos familiares torna a liberdade de escolha fundamental para sua constituição. Casamentos de conveniência e decisões da família de origens sobre o destino de seus filhos vão ficando cada vez mais distantes. (UZIEL, 2002).

Diante da tendência de inúmeras outras formas de composição familiar, põe-se em questão a compreensão tradicional de estabilidade familiar. Os vínculos estabelecidos na pós-modernidade já não são mais mediante uma rígida hierarquia de poder dentro da família, mas sim de igualitarismo, em que a mulher dentro da família já não assume um papel tão estigmatizado como antes. Não convém definir a composição familiar como tal, já que o arranjo familiar tradicional nuclear ainda existe como também por outro lado existem famílias monoparentais. Pode também oscilar entre hierarquizado e igualitário de um jeito confuso e muitas vezes contraditório. Apesar de uma difícil conceituação acerca de algo em mudança, é preciso levar em consideração um fato inegável: a transformação social na contemporaneidade.

Desse modo, foram elencados alguns aspectos da configuração familiar atual.

Apesar de tudo, a vida privada mesmo mostrando a incapacidade de demonstrar um conforto, continua sendo um refúgio, um lugar privilegiado da afetividade diante a agressiva falta de conteúdo da pós-modernidade.

\section{Refletindo sobre a sexualidade}

Ao longo da história a sexualidade vem se re-significando. Pensar na sexualidade pode parecer um assunto sem importância, um esgotamento de energia diante dos problemas mais graves como a guerra, racismo e pobreza, porém são produtos da atividade humana e também são permeados por conflitos de interesses ou por manobras políticas seja ela deliberada ou acidental, sendo assim a sexualidade vem sendo renegociada a todo o momento e isso deve ser considerado. Por outro lado, a sexualidade carece de estudos mais aprofundados. A Gayle S. Rubin explica que

\footnotetext{
Vários traços duradouros do pensamento sobre sexo inibem o desenvolvimento de uma teoria como essa. Essas idéias permeiam de tal forma a cultura ocidental que raramente são questionadas. Assim, elas terminam por ressurgir em contextos políticos diferentes, valendo-se de outro estilo para se exprimir, mas reproduzindo suas premissas básicas. (RUBIN, 1984).
}

Uma dessas premissas é o essencialismo sexual que considera o sexo como

\begin{tabular}{|l|l|l|l|l|l|}
\hline Interfaces da Educ. & Paranaíba & v. 1 & n. 3 & p.93-102 & 2010 \\
\hline
\end{tabular}


imutável, a-social e não histórico. Por muito tempo esse axioma foi reproduzido nos meios acadêmicos, porém nas últimas décadas o essencialismo foi questionado, foi mostrado que a homossexualidade é um complexo institucional e relativamente moderno. Foucault (1989) faz críticas às formas tradicionais de entender a sexualidade da forma essencialista e mostra como a noção acerca da sexualidade é constituída no curso de práticas sociais específicas da história. Assim como no modo de entender a homossexualidade no campo da sexualidade, Foucault (1989) defende o princípio de que a Homossexualidade é historicamente datada, pois depende da noção da sexualidade de cada um que é igualmente moderna. Ou seja, o conceito de homossexual é socialmente construído como qualquer outro. Nesse sentido, Nunan reitera,

Não há como manter a idéia de homossexualidade natural e trans-histórica, com base no suposto imperativo biológico da divisão cromossômica dos sexos, porque nessas crenças atuais sobre a realidade das diferenças de sexos foram construídas nos séculos XVIII e XIX. (NUNAN, 2003, p. 13).

A partir dessa época, foi possível pensar nos seres humanos como naturais e divididos em dois sexos (homem/mulher), assim pôde dar sentido a termos como a homossexualidade e heterossexualidade que são meras identidades socioculturais e molda a maneira de ver, viver e sentir, não sendo assim leis universais.

Houve também uma diferenciação sexual, ou seja, homens como ativos e superiores intelectualmente, e mulheres como passivas e superiores afetivamente. Surge a partir daí uma diferenciação de gêneros: o masculino e o feminino. Nesse processo de bissexualização dos corpos, trouxe consigo também a bissexualização do psiquismo, ou seja:

A mulher era um homem invertido e inferior e servia apenas para a reprodução da espécie humana. (Mas quando a mulher se torna o inverso complementar do homem, [...], a categoria de inversão (agora como antinatural e perverso), passa a designar o homossexual. (NUNAN, 2003, p. 25).

A inversão será então considerada uma perversão, pois o seu corpo de homem é portador da sexualidade feminina.

Sua inversão será perversão porque seu corpo de homem será portador da sexualidade feminina que acabara de ser citada. O invertido aprensenta um duplo desvio: sua sensibilidade nervosa e seu prazer sexual eram femininos. Seu sexo foi, por isso mesmo, definido como contrário aos interesses da reprodução biológica. (COSTA, 1995 apud NUNAN 2003, p. 15).

O homossexual começa a ser estudado rigorosamente junto com outros perversos já que eram considerados como tais, como uma grande ameaça à família, raça e sociedade. Assim, os sujeitos passaram a ser divididos em heterossexuais e homossexuais, categoria inexistente antes da construção da noção de homem/mulher.

Fora assim estudada a partir dos conceitos de instinto, degeneração e evolucionismo. Assim, o que fugia da finalidade de reprodução era considerado como um 
desvio ou perversão da meta natural. Naquela época, entre os séculos XVII e XIX, o termo corrente para designar os homossexuais era a palavra invertido. Dentro do campo de estudos, tentou-se fazer curas e teorias da medicina, que consideravam algo contagioso e poderia se constatar um homossexual pelas deformidades físicas (do pênis e ânus), adquiridas pelo uso. Porém, a noção de homossexualidade que surgiu na medicina oitocentista foi sendo integrada à psicologia e passou a ser explicada como um produto das histórias individuais. (NUNAN, 2003, p. 20).

A partir do século XIX, a sexualidade se tornou chave da individualidade permitindo uma melhor análise. A medicina passou a já não mais tratar como um comportamento sexual anormal, mas passou a pensar em identidades sexuais, tornando-se, na contemporaneidade do ocidente, uma das dimensões centrais da identidade social dos indivíduos. Porém, sempre se acaba classificando e no que poderia representar uma diversidade acabou se tornando uma prisão, no qual os homossexuais ainda são considerados no senso comum como anormais.

\section{Os processos e implicações do "coming out"}

Diante das barreiras existentes, devido ao forte preconceito postulado pela tradicional heteronormatividade, o indivíduo enfrenta uma série de dificuldades ao "sair do armário".

Quanto ao ser homossexual, não se pode considerá-lo uma escolha, pode-se dizer que o indivíduo pode escolher adotar ou não uma identidade gay. Quando decide adotar um "estilo de vida gay", enunciado pelo Foucault, o indivíduo tem que passar pelo rito de se assumir como tal, termos também utilizados como "sair do armário" ou "coming out", no que consiste em revelar a sua orientação sexual seja para seus familiares, amigos ou colegas, ganhando assim uma visibilidade desafiando o discurso sexual hegemônico. Em outras palavras, o sujeito faz opção de ser socialmente homossexual, mas não de desejar ser homossexualmente. (TREVISAN, 2000.).

O temor surge não necessariamente quando o sujeito se descobre homossexual, mas principalmente da consciência de que socialmente sofrerá rejeição. Por assim dizer, o temor consiste também em uma fase de encobrimento de sua orientação sexual, que é importante e, ao mesmo tempo, crítico e delicado no desenvolvimento de sua individualidade. Nunan (2003) continua afirmando que, em determinado momento, o indivíduo pode vir a sentir que o encobrimento não é mais necessário, pois ele se aceita e se respeita, não havendo a necessidade de esconder o estigma. (NUNAN, 2003).

Assumir para si é o ponto de partida de um árduo processo que ainda virá se o sujeito resolve se revelar para outras pessoas. Muito além das dúvidas de para quem, como e quando contar, o sujeito não sabe como as pessoas reagirão, arriscando perder conexões humanas importantes como a família e amigos íntimos.

Existe um grande medo de rejeição afetiva com a família e não tão incomum serem fisicamente agredidos ou até expulsos de casa. Por isso muitos decidem por conta desse temor, levar uma vida dupla, que não é muito saudável para o desenvolvimento de sua individualidade, pois mesmo indiretamente reprimidos na sua forma de expressão, não

\begin{tabular}{|l|l|l|l|l|c|}
\hline Interfaces da Educ. & Paranaíba & v. 1 & n. 3 & p.93-102 & 2010 \\
\hline
\end{tabular}


podem livremente expressar aquilo que realmente sentem.

A psicologia contribui muito no que diz respeito a esse processo de se assumir, pois mesmo levando em conta a peculiaridade que cada família traça para si, há uma regra geral para a homossexualidade, apesar dos processos e passos que devem ser tomados a cada situação. Muitas páginas da internet, no qual servem de apoio para os homossexuais que queiram se assumir, há um roteiro já estabelecido das prováveis situações e como o sujeito que pretende se assumir homossexual tem que se portar.

De um modo geral, abordam seis fases. O primeiro é o choque, quando os pais não sabiam acerca da homossexualidade de seu filho ou filha. É quando acontece o primeiro contato com a declaração da orientação sexual de deu filho ou filha, na qual é uma reação natural, porém é um caminho que inevitavelmente o sujeito passa, no processo de se assumir. É apontado que deve ser declarado aos pais que os ama muito e que continuarão sendo a mesma pessoa apesar de sua orientação sexual. Caso os pais já sabiam, é um passo dado a um caminho para uma segunda fase que é a negação. A negação é um escudo de proteção dos pais diante a uma declaração dolorosa para eles. As reações de negação podem ter muitas formas como a hostilidade, não dar ouvidos, indiferença ou rejeição. A percepção que eles terão será sobre o discurso aceito na sociedade. Achando que seu filho estaria confuso e levando até a um psicólogo para tentar um "tratamento". Em seguida, passa-se para a terceira fase, que é a de culpa, em que a mãe e o pai sentem que fizeram algo errado, não tendo criado seu filho adequadamente, e quando os pais são separados, se sentem ainda mais culpados por achar que a ausência de um deles foi determinante na orientação sexual de seu filho. Já a quarta fase, é a vez de se expressarem considerando as emoções, não tão incomum, são os sentimentos de raiva e mágoa. A tomada de decisão consiste-se na quinta fase, em que são colocados mais racionalmente os caminhos a seguir e colocam o filho numa encruzilhada de ter de optar, qual caminho seguir. Existem pais que apoiam seu filho, mas há outros que colocam uma pedra no assunto, continuam a fazer guerrilhas constantes, passando a ter diversas recaídas. A última fase, que nem todos chegam é a sexta. O caso de aceitar de fato a homossexualidade de seu filho. É quando refletem anedotas que ouviram, durante anos, sobre homossexuais, e passa a ter uma perspectiva diferente acerca da homossexualidade do filho.

Visto essas prévias orientações facilmente encontradas na internet, nota-se nesse processo de "se assumir" já definidas as formas de agir na família diante desse processo. Não é uma tarefa fácil, afirmar-se homossexual diante os outros, pois põe-se em risco a perda dos laços familiares, tendo de empenhar um enorme esforço psíquico diante das implicações a serem enfrentadas. Não se pode negar a contribuição da psicologia na elaboração de apoio aos que resolvem "sair do armário", porém, há de se analisar um pouco mais a fundo os processos sociais empreendidos dentro do contexto da luta de sua individualidade contra a heteronormatividade e a velação de sua sexualidade. Sobre a sexualidade, Nunan reitera que para os homossexuais, assumir a sexualidade em público significa contar justamente o que os outros escondem, isto é, a vida sexual, que em nossa sociedade pertence à esfera privada. (NUNAN, 2003). Atualmente, é dentro da família que existe uma esfera privada, porém um pouco deturpada da ordem do discurso tradicional de família, sendo assim um lugar de refúgio das implicações cotidianas individualistas. 
A rejeição da heteressexualidade cultural é estressante tanto para o indivíduo que fora socializado neste modelo como também para sua rede social, que tem a partir desse momento do "coming out" expectativas quebradas e quer construir novas perspectivas, é um empreendimento de tempo, informação e compreensão. Ao revelar sua homossexualidade, o sujeito se comporta de acordo com seus princípios e ética pessoal, e, ao mesmo tempo, arrisca a ter perdas sociais e a sofrer sanções. O "coming out" deveria ser encarado como um dos processos de aprendizagem social mais importantes na vida de um homossexual. (NUNAN, 2003).

Se há questionamento das crenças e das normas sociais, é possível entender assim o processo de afirmação de sua orientação sexual, como uma quebra das noções estabelecidas e aprendidas na sociedade de um modo geral e assim, novas crenças podem vir a substituir. Ao contrário de membros de outros grupos estigmatizados como religioso ou étnico, os homossexuais não tem geralmente apoio e atitudes protetora pela família, pois são criados geralmente por pais e mães heterossexuais, onde se torna na família um campo fértil para a promoção de um preconceito sexual.

Desse modo, a família perde relativa centralidade nesse contexto, principalmente. antes do "coming out", em que o sujeito ainda não tem uma referência do que é ser e viver como homossexual, a não ser do modelo da família heterossexual, baseando-se, assim, em imagens distorcidas veiculadas também pelos meios de comunicação. (GROSS, 1996 apud NUNAN, 2003).

Pode-se, também, considerar que é uma forma de auto-estigmatização o ato de se assumir homossexual, pois são identificados erroneamente de forma estereotipada devido à identidade de gênero não ser aceita socialmente. Como no caso de um homem homossexual de gênero masculino, é identificado como invertido por ser homossexual, sendo rotulado como mulher. Assim, um interessante paradoxo emerge quando da criação da identidade homossexual: ela simultaneamente erotiza e viola a masculinidade.

Ao se assumir, o sujeito está ciente que pode ser subvertido pelas pessoas em seu gênero, posição social e política, a qual foi determinada pelo discurso heterossexual. É uma situação delicada, que ao mesmo tempo que liberta, estereotipa.

\section{Considerações finais}

Não se pode negar que a família ainda ocupe um lugar-chave na socialização das novas gerações. As mudanças ocorridas na esfera da sexualidade, normalmente são relacionadas com modernização dos costumes sexuais.

Contudo, estas mudanças não fornecem ao sujeito a oportunidade de modernizar seu funcionamento real e profundamente, nos seus conteúdos e na sua identidade. Talvez o único modo de conseguir ser "pós-moderno" seja tentar acompanhar as transformações através de uma modernização do comportamento. (BORGES, 2009, p. 120).

Mesmo não tendo modernizado completamente o nosso comportamento, a diversidade sexual continua a aumentar como também os discursos masculinos e femininos 
começam a não estar mais tão nítidos em seus preconceitos. De uma sociedade hierarquizada, a sociedade vem se modificando para o igualitário, do modo que a brutalidade dos preconceitos é inibida. Digo inibida, pois não podemos traçar roteiros, pois numa situação como no processo de "sair do armário" espera-se inúmeras reações. Reações que por sua vez também não podemos definir, já que não podemos definir precisamente a família.

Sarti (2004) defende que a família é auto-referida, em que o "nós" constitui um mundo privado, influenciado pelo mundo exterior e público e tem de lidar com a dimensão do "outro". Se não considerarmos o "outro" que é a condição da existência do "nós", dialeticamente não faria sentido.

A sensação de estar em casa no mundo pós-moderno, prescinde da experiência espacial da casa, então os filhos quando estão em conflito com os pais, sentem-se mais em casa com o seu grupo de afirmação identitária do que com a família que é vista como estranha. Ou seja, não é possível buscar referências homossexuais numa família de heterossexuais, por isso o jovem precisa buscar, na maioria das vezes, grupos de afirmação que condizem com o que sente e pensa.

Nesse caso, a família perde certa centralidade, porém ela é importante por manter o eixo de referências simbólicas, apego, segurança, rede de proteção, mesmo abrindo também espaços para o outro, continuará sendo o ponto de refúgio. Mesmo a família deixando de ser o centro na vida do indivíduo, na medida em que os indivíduos se portam de acordo com os movimentos da contemporaneidade, ou seja, com uma vida socialmente instável, a família serve como um refúgio para a afetividade que ainda lhe resta. Quando esse espaço lhe é negado, no caso de um homossexual que assume sua orientação sexual, de fato, a família deixa de ser referência, mas não de apoio.

\section{Referências}

BORGES, Roberta Costa. Pais e mães heterossexuais: relatos acerca da homossexualidade de filhos e filhas, 2009. Dissertação (Mestrado em Psicologia) - USP - Ribeirão Preto, 2009.

FOUCAULT, Michel. História da Sexualidade. A vontade de saber. Rio de Janeiro: Graal, 1989. V.1.

NUNAN, Adriana. Homossexualidade: do preconceito aos padrões de consumo. Rio de Janeiro: Caravansarai, 2003.

Rubin, Gayle. Pensando sobre sexo: notas para uma teoria radical da política da sexualidade. Campinas, Mimeo, 2003.

SANTOS, Claudilene. A parentalidade em familias homossexuais com filhos: um estudo fenomenológico da vida de gays e lésbicas, 2004. Tese (Doutorado em Psicologia) - USP Ribeirão Preto, 2004.

\begin{tabular}{|l|l|l|l|l|l|}
\hline Interfaces da Educ. & Paranaíba & v. 1 & n. 3 & p.93-102 & 2010 \\
\hline
\end{tabular}


SARTI, Cynthia Andersen. A família como ordem simbólica. Psicologia USP, São Paulo, v.15, n.3, p. 11-28, 2004.

TREVISAN, J.S. Devassos no paraíso: A homossexualidade no Brasil, da colônia à atualidade. 3. ed. Rio de Janeiro: Record, 2000.

UZIEL, Anna Paula. Familia e homossexualidade: velhas questões, novos problemas, 2002. Tese (Doutorado em Antropologia) - Universidade Estadual de Campinas -

Campinas, 2002. 